\title{
Liver metastasis is established by metastasis of micro cell aggregates but not single cells
}

\author{
KAZUHIKO KASUYA, YUICHI NAGAKAWA, YUICHI HOSOKAWA, YATSUKA SAHARA, CHIE TAKISHITA, \\ TETSUSHI NAKAJIMA, YOSUKE HIJIKATA, RYOKO SOYA, KENJI KATSUMATA and AKIHIKO TSUCHIDA
}

Department of Gastrointestinal Surgery, Tokyo Medical University, Shinjuku-ku, Tokyo 160-0023, Japan

Received December 1, 2015; Accepted January 6, 2017

DOI: $10.3892 / e t m .2017 .4470$

\begin{abstract}
Cancer cell engraftment in the target organ is necessary to establish metastasis. Clinically, lymph node metastasis of single cells has been confirmed using cytokeratin staining. In the current study, a LacZ-labeled cancer cell line was used to visualize intrahepatic metastasis of single cells or liver micrometastasis. KM12SM-lacZ stably expressing LacZ was prepared with a highly metastatic colon cancer cell line, KM12SM. KM12SM-lacZ was injected into the spleen of nude mice and following 1 week the spleen was excised. The liver was then examined for metastasis following 1, 2 or 3 weeks. Confirmation of liver metastasis was completed by observing the grade of metastasis. Grade-1 metastasis (DNA level), human DNA in liver tissue was detected; Grade-2 metastasis (metastasis of single cells), confirmed by X-gal staining; Grade-3 metastasis (histopathological micrometastasis), diagnosed by light microscopy and Grade-4 metastasis (typical metastasis), easily detected macroscopically or by hematoxylin and eosin staining. The Grade- 1 metastasis detection rates 1, 2 and 3 weeks following splenectomy were 50, 100 and $100 \%$, respectively. Grade-2 metastasis was not detected by microscopy. The Grade- 3 metastasis detection rates for 1,2 and 3 weeks were 75, 100 and $100 \%$, respectively. Micrometastasis was observed in the portal vein lumen and wall. The Grade-4 metastasis detection rates were 50, 100 and $100 \%$ for 1, 2 and 3 weeks respectively. Cancer cells were present in vessels surrounding the main tumor. In conclusion, a specific number of cancer cell aggregates may be necessary to establish hematogenous metastasis.
\end{abstract}

Correspondence to: Dr Kazuhiko Kasuya or Dr Akihiko Tsuchida, Department of Gastrointestinal Surgery, Tokyo Medical University, 6-7-1 Nishishinjuku, Shinjuku-ku, Tokyo 160-0023, Japan

E-mail: kasuya-k@jcom.home.ne.jp

E-mail: akibobo@hotmail.com

Key words: liver metastasis, micrometastasis, colon cancer, LacZ

\section{Introduction}

Colorectal cancer is a disease localized to the colon that may cause hematogenous liver metastasis, lymphogenous lymph node metastasis and disseminated metastasis when it becomes advanced. Among these, liver metastasis has the highest frequency of occurrence and the strongest influence on cancer prognosis (1). Currently the only effective treatment for increasing the long-term survival rate of patients with liver metastasis is hepatectomy $(2,3)$. However, the rate of recurrence in the remnant liver remains high, possibly due to incomplete resection of the metastasis, which in turn may be due to the existence of smaller cancer cell nests $(2,3)$. A standard approach to multi detector-row computed tomography (MDCT) of the liver is to acquire images with a slice thickness of $1 \mathrm{~mm}$ and perform multiphase dynamic CT and multiplanar reformation. Magnetic resonance imaging (MRI) of the liver consists of gadolinium ethoxybenzyl diethylenetriamine pentaacetic acid-enhanced dynamic MRI combined with diffusion-weighted MRI, requiring a slice thickness of 2-3 mm (4). Advances in imaging techniques have enabled the visualization of minute lesions that are undetectable by conventional CT or ultrasonography. Incomplete resection allows cancer cells to spread into the abdominal cavity from cancer lesions penetrating the intestinal wall (5). Metastasis is not established by the simple presence of cancer cells, as cancer cell engraftment in the metastasis-target tissue is necessary. Therefore, the establishment of metastasis is influenced by host factors including immune cells and the blood flow environment, in addition to cancer cell factors, such as high permeative and cytoadherent properties (6). Considering the influence of the host side, the question of whether or not a single cell may cause metastasis arises. Metastasis of single cancer cells that metastasized to a lymph node have been detected by cytokeratin staining (7), but no hematogenous liver metastasis of single cells has been identified. It was suggested that this may be due to rapid portal blood flow compared with lymph flow, generating a difference in viability between single cells floating in portal blood and lymph nodes (7). In addition, phagocytes, such as Kupffer cells, are abundant in the liver and should inhibit cancer cell engraftment Therefore, a specific number of cells that form a cancer cell nest may be necessary to establish liver metastasis (8); however, the number of cells required to initiate metastasis is currently unknown. 
In addition, difficulties lie in distinguishing single cells and/or ultra small nests from the diverse cells present in the liver. Identifying a single cell and/or an ultra small nest in the liver is expected to be more difficult than detection in lymph nodes, which do not possess epithelial-system cells (7). The present study used a LacZ-labeled cancer cell line to visualize intrahepatic metastasis of single cells or liver micrometastasis.

\section{Materials and methods}

Cells. The human colon cancer cell line, KM12SM was provided by Dr Nakajima at SBI Pharmaceuticals Co., Ltd., (Tokyo, Japan) (9). Cells were cultured for 2 days at $37^{\circ} \mathrm{C}$ in Roswell Park Memorial Institute medium-1640 (Thermo Fisher Scientific, Inc., Waltham, MA, USA) supplemented with $10 \%$ fetal calf serum (Sigma-Aldrich; Merck KGaA, Darmstadt, Germany) and $1 \%$ penicillin and streptomycin (Thermo Fisher Scientific, Inc.) within the total medium volume under a humidified atmosphere containing $5 \% \mathrm{CO}_{2}$.

Production of KM12SM-LacZ vectors. The production of a LacZ-manifested retrovirus was quantified using TransIT-293 (Mirus Bio LLC, Madison, WI, USA), according to the manufacturer's instructions. Briefly, the LacZ expression vector was constructed using a pDON-5 DNA vector (Clontech Laboratories, Inc., Mountain View, CA, USA) by inserting a Kozak sequence (GCCCCACC) and the lacZ coding region from a pSV- $\beta$-Galactosidase control vector (all from Promega Corporation, Madison, WI, USA). The lacZ coding region in the vector began with the 7th amino acid of the wild-type lacZ gene (Full sequence for pSV-beta-Galactosidase at https://www. addgene.org). G3T-hi cells (Takara Biotechnology Co., Ltd., Kusatsu, Japan) were sprayed into $60 \mathrm{~mm}$ collagen-coated plates (Cosmo Bio Co., Ltd., Tokyo, Japan) at a density of $2-3 \times 10^{6}$ cells/dish and were cultured for 1 day at $37^{\circ} \mathrm{C}$. Prior to cell transfection, G3T-hi cells were grown to $70-80 \%$ confluence in a petri dish. The following protocol was used for cell transfection: A total of $250 \mu \mathrm{l}$ Opti-MEMI Reduced-Serum Medium (Thermo Fisher Scientific, Inc.) was added to a sterile tube. Subsequently, $2 \mu \mathrm{l} \mathrm{LacZ}$ expression vector $(1 \mu \mathrm{g} / \mu \mathrm{l}), 2 \mu \mathrm{l}$ pGP Vector (Takara Biotechnology Co., Ltd.), $1 \mu \mathrm{l}$ pE-ampho Vector (Takara Biotechnology Co., Ltd.) were added and a pipette was used to gently mix all reagents completely. Then, $7.5 \mu 1$ TransIT-293 reagent (Mirus Bio LLC) was warmed to room temperature and pipetted into the mixture. The mixture (DNA-TransIT complex) was then incubated at room temperature for $30 \mathrm{~min}$. A total of $262.5 \mu \mathrm{l}$ DNA-TransIT complex, $62 \mu 12 \mathrm{M}$ calcium chloride and distilled water were mixed in a $5 \mathrm{ml}$ polystyrene round-bottom tube to $500 \mu \mathrm{l}$ (DNA mixture). The culture medium was prepared using $10 \%$ fetal bovine serum (FBS; GE Healthcare Bio-Sciences, Pittsburgh, PA, USA) and Dulbecco's modified Eagle's medium high glucose (DMEM, Sigma-Aldrich; Merck KGaA) with 25 mM chloroquine (1:1,000). The supernatant was aspirated and discarded by an electric pipette from the G3T-hi cells and $3 \mathrm{ml}$ culture medium was added. The DNA mixture was added slowly to $500 \mu 1$ transfection buffer (Mirus Bio LLC). A pipette was used to immediately mix this for $10-20 \mathrm{sec}$. Then, $1,000 \mu \mathrm{l}$ DNA mixture was dropped evenly into a petri dish using an electric pipette, then mixed within 1-2 min and cultured in $5 \% \mathrm{CO}_{2}$. A total of $24 \mathrm{~h}$ following transfection, the medium was replaced with DMEM plus FBS. After a further $24 \mathrm{~h}$, supernatant was filtered through a $0.45-\mu \mathrm{m}$ filter and the resulting solution was used as a LacZ gene expression retrovirus vector solution. The retroviral vector solution was aliquoted and stored at $-80^{\circ} \mathrm{C}$.

Construction of KM12SM-LacZ. KM12SM was seeded during the logarithmic growth phase in a 6-well plate with $8 \times 10^{4}$ cells/well. Following $24 \mathrm{~h}, 1.2 \mathrm{ml} \mathrm{LacZ}$ expression vector and $1.2 \mu \mathrm{l}$ polybrene solution $(8 \mathrm{mg} / \mathrm{ml}$; Sigma-Aldrich; Merck KGaA) were added to $1 \mathrm{ml} \mathrm{KM12SM}$ in each well after medium was removed. The medium was changed to a medium containing $300 \mu \mathrm{g} / \mathrm{ml}$ of Geneticin (Thermo Fisher Scientific, Inc.) $24 \mathrm{~h}$ after the virus infection. Cells resistant to geneticin were harvested $14 \mathrm{~d}$ later and stored at $-80^{\circ} \mathrm{C}$ in a Cellbanker 1 (1x10 ${ }^{6}$ cell/vial; Takara Biotechnology Co., Ltd.).

To confirm the expression of LacZ, X-gal staining was completed. KM12SM-LacZ cells were cultured in the medium with geneticin for $24 \mathrm{~h}$ at $37^{\circ} \mathrm{C}$. To complete the X-gal staining, a fixative agent was added to KM12SM-LacZ cells cultured on a prepared slide, and incubated for $5 \mathrm{~min}$ at room temperature. The composition of the fixative agent was $1 \%$ neutral formalin solution (Muto Pure Chemicals Co., Ltd., Tokyo, Japan), $0.2 \%$ glutaraldehyde (Wako Pure Chemical Industries, Ltd., Osaka, Japan), 0.02\% Tergitol solution (Sigma-Aldrich; Merck $\mathrm{KGaA}$ ) and phosphate-buffered saline. The staining solution was then added to the KM12SM-LacZ cells and incubated for $3 \mathrm{~h}$ at $37^{\circ} \mathrm{C}$. The stain solution was composed of $5 \mu \mathrm{m}$ hexacyanoferrate (II) potassium (Wako Pure Chemical Industries, Ltd.), $5 \mu \mathrm{m}$ hexacyanoferrate (III) potassium (Wako Pure Chemical Industries, Ltd.), 0.02\% Tergitol solution (Sigma-Aldrich; Merck KGaA), $2 \mu \mathrm{m} \mathrm{MgCl}$ (Wako Pure Chemical Industries, Ltd.) and $2 \mathrm{mg} / \mathrm{ml} \mathrm{X-gal} \mathrm{(Promega} \mathrm{Corporation).}$

Mouse liver metastasis model using KM12SM-LacZ. A total of 12 athymic BALB/c male nude mice with a body weight (BW) of 20-22 g (nu/nu; 6-8 weeks old) were obtained from CLEA Japan, Inc. (Tokyo, Japan). Animals were kept at the Animal Care and Use Facilities at Tokyo Medical University Hospital (Tokyo, Japan) under specific pathogen-free conditions. Animals were individually housed in cages at a temperature of $22-24^{\circ} \mathrm{C}$ and relative humidity of $60-65 \%$ in a 12 h light/dark cycle. Mice feed (CA-1; CLEA Japan, Inc.) was given ad libitum following high-pressure steam sterilization. All experiments were approved by the Animal Care and Ethics Committee of Tokyo Medical University. For all operative procedures, animals were anesthetized with an intraperitoneal injection of $1 \mu \mathrm{l}$ saline supplemented with $0.75 \mathrm{mg} / \mathrm{kg}$ BW medetomidine (Asco Co., Ltd., Toyohashi, Japan), $0.75 \mathrm{mg} / \mathrm{kg}$ BW midazolam (Sandoz Inc., Princeton, NJ, USA) and $5.0 \mathrm{mg} / \mathrm{kg}$ BW butorphanol (Asco Co., Ltd.).

KM12SM-lacZ was suspended using Hank's balanced salt solution (Thermo Fisher Scientific, Inc.) to produce a $5 \times 10^{5}$ cells $/ 50 \mu \mathrm{l}$ per mouse cell suspension. The cell suspension was placed in a $1 \mathrm{ml}$ syringe kept on ice until use. The mice underwent surgery to create a $1 \mathrm{~cm}$ incision above the spleen, to move the spleen into the external abdominal cavity, following anesthesia as described above. The cell suspension was slowly injected under the splenic capsule using a 29-gauge needle. The puncture hole was compressed using a 
cotton swab in order to avoid leakage of the cell suspension and hemostasis. Following 1 week, re-incision of each mouse was completed and the spleen was removed under the aforementioned anesthesia. Mice were sacrificed by intravenous administration (100-120 mg/kg) of pentobarbiturate (Kyoritsu Seiyaku Co., Ltd., Inc., Tokyo, Japan) into a tail vein 1, 2 or 3 weeks following splenectomy and the liver was excised ( $n=4$ randomly selected mice per group). The excised liver was initially examined by the naked eye to confirm the presence or absence of macroscopic nodule. To avoid cancer cell contamination, lobes with no observable nodule growth were set aside for DNA sampling. The remaining lobes were then divided into two equal groups. Lobes in one group were fixed for $2 \mathrm{~d}$ in $10 \%$ neutral buffered formalin (Wako Pure Chemical Industries, Ltd.) at room temperature and embedded in paraffin for histological diagnosis. The remaining lobes were stored for $2 \mathrm{~d}$ at $-80^{\circ} \mathrm{C}$ for $\mathrm{X}$-gal staining. Liver for pathological examination was cut in 2-mm sections and stained using hematoxylin and eosin (H\&E). Frozen specimens, once cut into sections $10 \mu \mathrm{m}$ thick were stained using X-gal. To stain the nucleus and the cytoplasm, Nuclear Fast Red stain (Vector Laboratories, Burlingame, CA, USA) was added.

Confirmation of liver metastasis. Grade-1 metastasis (DNA level), human DNA (Chromosome 17-Specific Alfa Satellite DNA) $(10,11)$ was detected. Genomic DNA was isolated from liver tissue exhibiting no observable tumor growth using a DNeasy ${ }^{\circledR}$ Blood \& Tissue kit (Qiagen GmbH, Hilden, Germany). The DNA from KM12SM cells was used as a positive control and that from mouse liver cells treated with distilled water was used as a negative control. The target site in the isolated DNA was amplified by polymerase chain reaction (PCR), which was performed using a total volume of $50 \mu \mathrm{l}$ in the presence of $100 \mu \mathrm{g}$ of isolated DNA, AmpliTaq Gold ${ }^{\circledR} 360$ Master mix (Applied Biosystems; Thermo Fisher Scientific, Inc.) and $0.25 \mu \mathrm{M}$ of each primer. Primers for human chromosome 17, detected in Grade-1 metastasis, were as follows: Forward, 3'-GGGATAATTTCAGCTGACTAAACAG-5' and reverse, 3'-TTCCGTTTAGTTAGGTGCAGTTATC-5'. The PCR conditions were as follows: An initial denaturation step for $10 \mathrm{~min}$ at $95^{\circ} \mathrm{C}$, then 35 cycles of denaturation for $1 \mathrm{~min}$ at $90^{\circ} \mathrm{C}$, annealing/elongation for $1 \mathrm{~min}$ at $60^{\circ} \mathrm{C}$ and a final elongation step for $10 \mathrm{~min}$ at $72^{\circ} \mathrm{C}$. Samples were then stored at $4^{\circ} \mathrm{C}$ for $12 \mathrm{~h}$ prior to electrophoresis. The target product $(850 \mathrm{bp})$ was confirmed using a $1.5 \%$ agarose gel. Grade- 2 metastasis (metastasis of single cells) was confirmed using X-gal staining (calculated as follows: X-gal-positive cell area/liver area X100). $\mathrm{X}$-gal stained sections were imaged using a Nano Zoomer-XR Digital slide scanner (Hamamatsu Photonics K.K., Shizuoka, Japan) and the image data was imported into the Tissue Studio ${ }^{\circledR}$ version 4.0 (Definiens, Munich, Germany). A total of $5 \mathrm{spec}$ ulum images of the data from liver cross sections, with the exception of the macroscopic liver metastasis were randomly selected. X-gal positive cells were detected using the image analyser. Grade-3 metastasis (histopathological micrometastasis) was diagnosed using light microscopy on specimens cut into $1-\mathrm{mm}$ sections. Nodules were of various sizes $(<1 \mathrm{~mm}$ to several $\mathrm{mm}$ in diameter) and not exposed on the liver surface, and could not be observed by the naked eye. Grade- 4 metastasis (typical metastasis) was detected macroscopically.

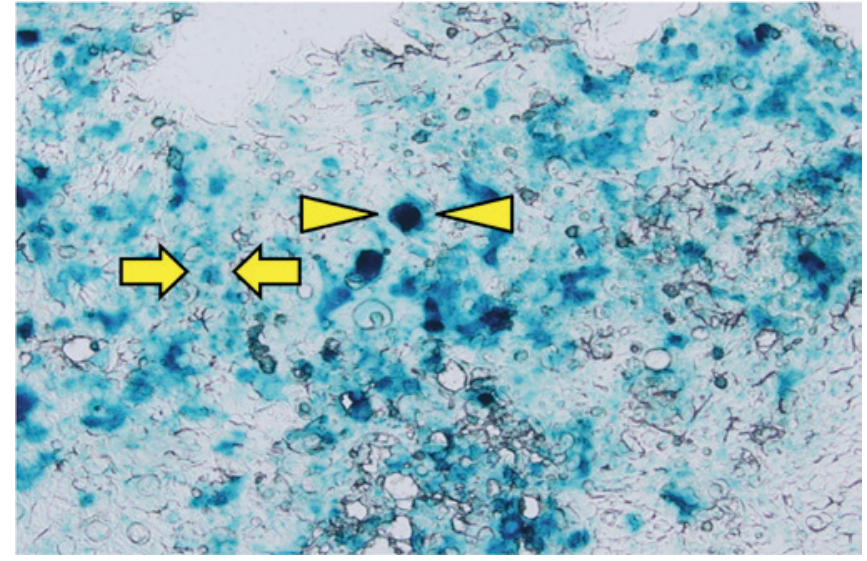

Figure 1. X-gal staining of KM12SM-LacZ under an inverted microscope (magnification, $\mathrm{x} 200$ ). X-gal positive cells were identified by blue staining of their cytoplasm (arrow heads and arrows).

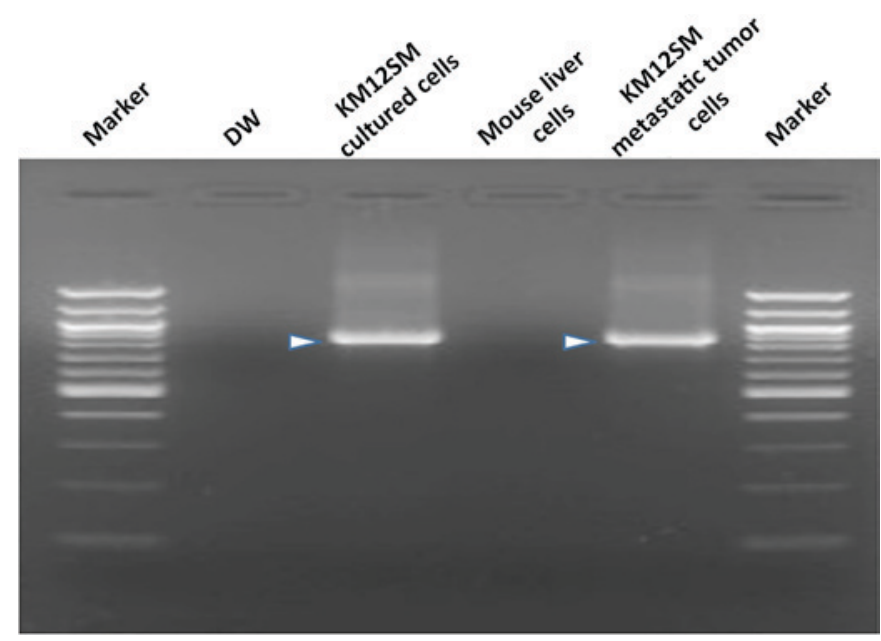

Figure 2. Detection of a human DNA by PCR. Bands of 850 bp were observed in the PCR products of metastatic KM12SM tumor tissue and cultured KM12SM cells, as a positive control. No bands were observed in the PCR products obtained from mouse liver cell treated with distilled water, as a negative control. White arrow heads indicate the $850 \mathrm{bp}$ bands. The marker shown was a 100 bp DNA ladder. DW, distilled water control group; PCR, polymerase chain reaction; bp, base pairs.

\section{Results}

Confirmation of KM12SM-LacZ. Histological analysis demonstrated that the morphology of cells transfected with KM12SM-LacZ and KM12SM were the same (data not shown). X-gal positive cells in the KM12SM-LacZ group were identified in approximately half of cells (Fig. 1). No $\mathrm{X}$-gal positive cells were observed in the KM12SM group (data not shown).

Confirmation of liver metastasis. The presence of target bands (850 bp) observed in the DNA extracted from cultured and metastatic KM12SM cells (Fig. 2) indicated that metastasis was present. Samples from non-tumorigenic mice liver lobes were considered to be positive for grade 1 metastasis when bands of $850 \mathrm{bp}$ were observed in PCR products. Detection rates at 1,2 and 3 weeks post-splenectomy were 50, 100 and $100 \%$, respectively. 

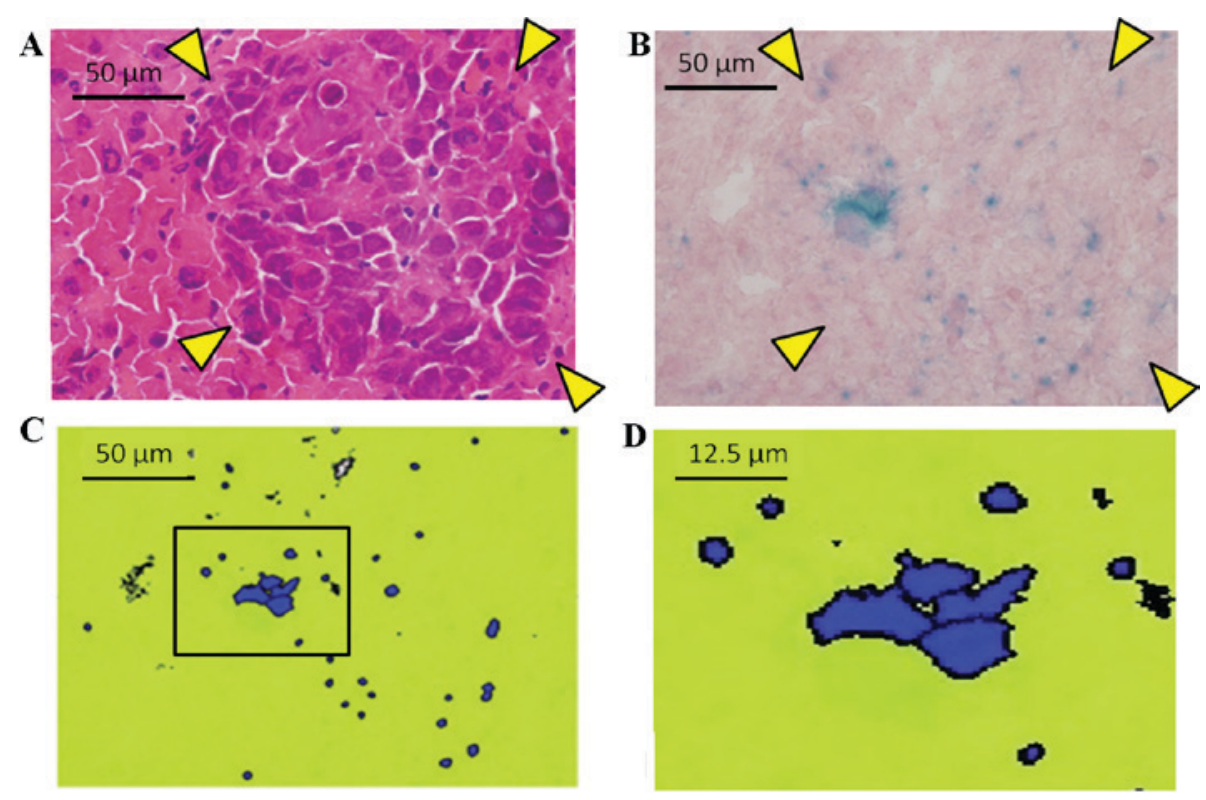

Figure 3. Liver metastases of KM12SM-LacZ. (A) Hematoxylin and eosin staining of frozen sections. The yellow arrowheads indicate the edges of a tumor (magnification, x200). (B) X-gal staining identified tumorogenic tissue within the frozen sections (arrow heads) (magnification, x200). (C) Digital imaging of X-gal staining (blue) (magnification, x200). (D) Expansion of highlighted region in C (Scale bars shown).

Grade-2 metastasis was not detected by microscopy. Therefore, Grade-2 metastasis was confirmed by X-gal staining (Fig. 3) and the total amount was calculated by the ratio of X-gal-positive cell area/liver area $\mathrm{x} 100$. As a result, the LacZ-positive area ratio was $1.28 \%$ in the tumor and $0.14 \%$ in the non-tumor section (Fig. 4).

Grade-3 metastasis detection rates were 75,100 and $100 \%$ for 1,2 and 3 weeks, respectively. Some lesions exhibited no surface exposure (Fig. 5A) Micrometastasis was observed in the portal vein lumen and wall (Fig. 5B and C). An inflammatory cell cluster (15-20 cells) that was similar in appearance to the cancer cell cluster was also observed in the liver (Fig. 5D) The inflammatory cells were smaller than hepatocytes and exhibited weak cellular adhesion and thin nuclear chromatin, indicating the presence of plasma cells.

Grade- 4 metastasis detection rates at 1, 2 and 3 weeks were 50, 100 and $100 \%$, respectively, and microscopic metastatic nodules were observed on the liver surface (Fig. 6A-C). Cancer cells were also present in vessels surrounding the main tumor (Fig. 6D). Detection rates for each metastatic grade are presented in Table I.

\section{Discussion}

Control of liver metastasis is crucial in the treatment of colon and rectal cancers. A number of animal models for liver metastasis have been assessed and two methods have been used: Tumor cell injection under the splenic capsule (splenic injection method) or transplantation of tumor cells under the cecal serosa (cecal method) (12-15). The splenic injection method is advantageous as the tumor cell injection technique is relatively easy, the formed tumor nodule does not affect survival of the animal and it is a mouse model. The disadvantage is that the location of the cancer cell-transplanted region is not the colon, so the model is not orthotopic in the strict sense. By contrast, in the cecal method the tumor is



Figure 4. Grade-2 metastasis. Comparison of X-gal staining in the positive area of the non-tumor area and the tumor area. The $\mathrm{Y}$ axis represents the area of X-gal positive sections/total area x 100 .

transplanted under the cecal serosa, which is an exquisite orthotopic transplantation model. A disadvantage of the cecal method is that tumor cell engraftment in the cecum takes 5 weeks, it causes liver metastasis, lung and disseminated peritoneal metastases and the handling of a rat model is difficult (12). To investigate a reliable 'model with liver metastasis alone', the present study adopted the splenic injection method. In addition, cancer cells were transplanted into the spleen, and the spleen was excised following 1 week. Takiguchi et al (15) also used a KM12SM transplantation model, employing the splenic injection method, but the spleen was not excised and the splenic tumor grew to a very large size. 

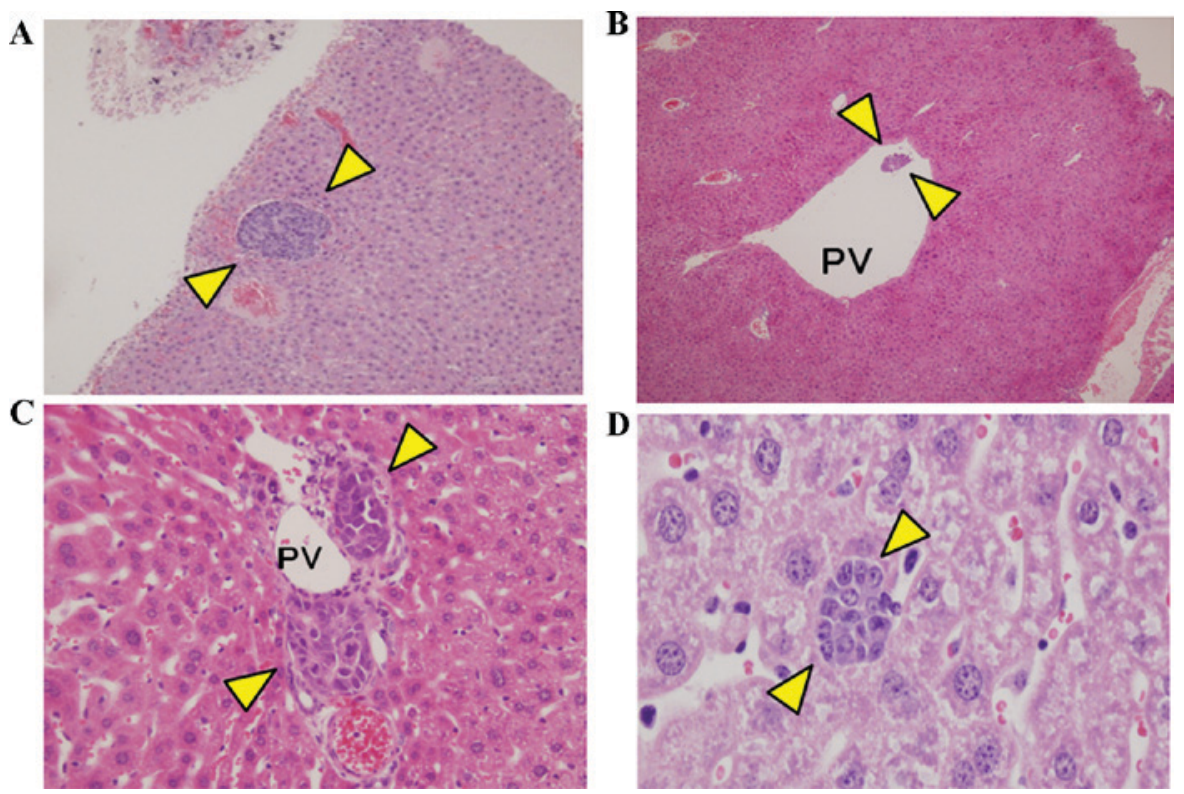

Figure 5. Grade-3 metastasis. (A) The lesion has no exposure to the liver surface. Arrow heads indicate the cancer cell cluster (low power magnification, x100). (B) Suspended cancer cell mass in a relatively thick PV (major and minor axis of 778 and $492 \mu \mathrm{m}$, respectively). Arrow heads indicate the cancer cell cluster within the PV (magnification, x100). (C) Clusters of tumor cells adhered to the PV wall (arrow heads; magnification, x200). (D) An inflammatory cell cluster (15-20 cells; arrow heads) in the liver, typically mistaken as micrometastasis. The inflammatory cells were smaller than hepatocytes and exhibited weak cellular adhesion and thin nuclear chromatin, indicating the presence of plasma cells (magnification, $\mathrm{x} 400$ ). All images represent samples obtained from different mice. PV, portal vein.
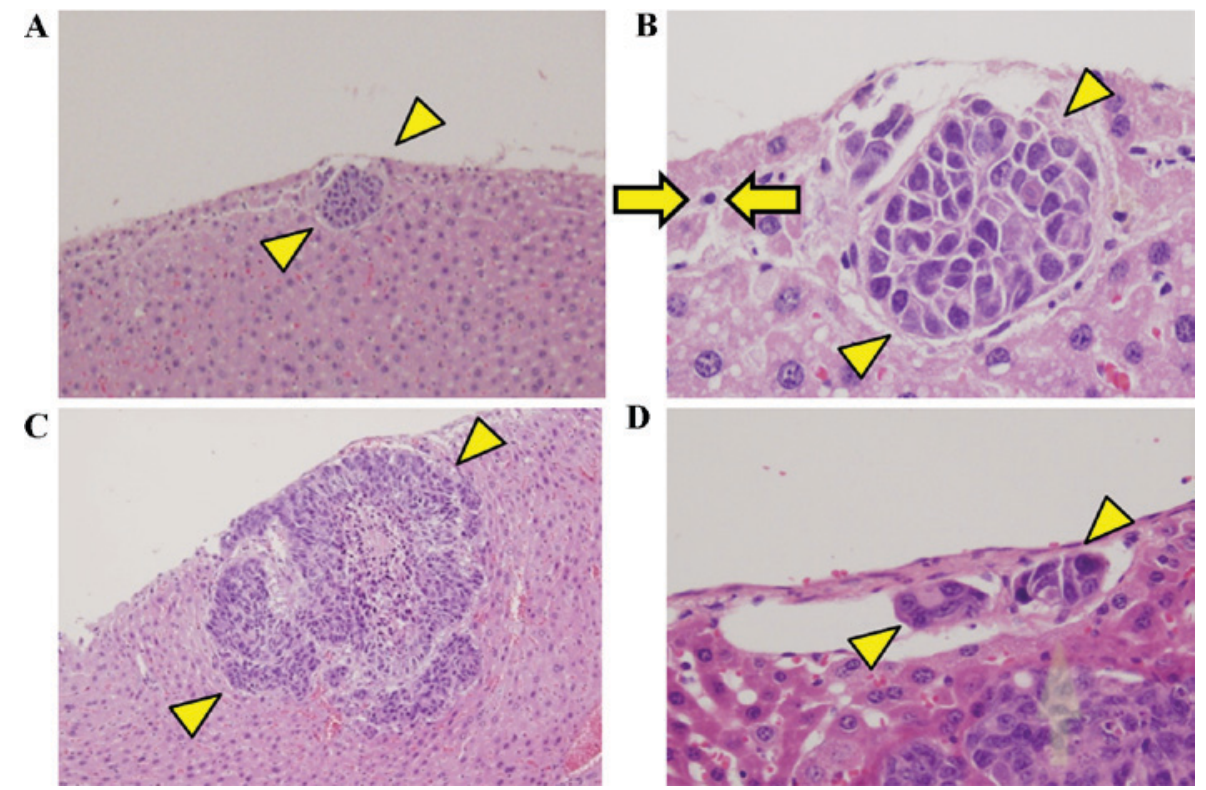

Figure 6. Grade-4 metastasis. (A) Visible tiny metastatic nodules on the liver surface (magnification, x100). (B) Expansion image of A. Since each cell is same size of surrounded hepatocytes, the nuclear chromatin is dense and accompanied with atypia, the cluster was diagnosed with cancer cells (magnification, $\mathrm{x} 400$ ). (C) Typical macroscopic metastases were observed as white nodules on the liver surface (magnification, $\mathrm{x} 100)$ and (D) vascular and lymphtic invasion of cancer cells were observed surrounding the visible metastases (magnification, x400). Arrow heads indicate cancer cells and all images represent samples obtained from different mice.

The aim of the current study was to detect 'small metastasis' or 'micrometastasis'. Although the criteria for micrometastasis remain unclear, when a small number of cancer cells are undetectable in conventional $\mathrm{H} \& \mathrm{E}$-stained preparations but are detected in a metastasis-target organ, it is generally considered micrometastasis. There are two primary micrometastasis detection methods: Detection of protein specifically expressed on cancer or epithelial cells by immunostaining and detection of DNA and mRNA using molecular-biological methods. The representative method of the former is cytokeratin staining (7). Cancer cells are epithelial cells and contain cytokeratin. By contrast, cells in blood and primary cells of lymph nodes (lymphocytes) when the metastasis-target is a lymph node, do not contain cytokeratin. When low levels of cytokeratin-positive cancer cells are present in these cytokeratin-negative environments, even a small number of cancer cells may be clearly 
Table I. Detection rate of metastases.

\begin{tabular}{lrrr}
\hline & \multicolumn{3}{c}{ Week } \\
\cline { 2 - 4 } Grade & $1(\%)$ & $2(\%)$ & $3(\%)$ \\
\hline 1 & 50 & 100 & 100 \\
2 & 0 & 0 & 0 \\
3 & 75 & 100 & 100 \\
4 & 50 & 100 & 100 \\
\hline
\end{tabular}

distinguished using cytokeratin staining. This method is used in clinical practice to detect micro lymph node metastasis using CAM5.2 and circulating tumor cells (CTC) (16). The representative method of the latter is the detection of cancer-specific DNA using PCR. Nomoto et al (17) detected micrometastasis of pancreatic cancer using a pancreatic cancer-specific point mutation in codon 12 of the K-ras gene in liver tissue and regarded it as latent metastasis. However, this method should be employed carefully because when PCR is performed using a DNA template, fragmented or dead cancer cells and active cancer cells are equally judged to be positive. To prevent false positivity, a fluorescent dye strongly binding to the DNA of viable cells, such as DAPI may be used to detect CTC (16). PCR using an mRNA template may be used to solely judge the activity of viable cells (18), but mRNA is readily degraded and not easy to handle. To detect cancer cells, which reached the liver including dead cells and DNA fragments, the target to human cell-specific chromosome was used in the present study and cancer cells in the liver were detected at a high rate in the model. In addition, to visualize micrometastasis of viable cells, the lacZ gene was introduced to label cells in order to detect them in situ. Arlt et al (19) detected single cell-foci in the blood, withdrawn from the lung prior to sacrifice using osteosarcoma cells stably expressing LacZ, Dunn-LacZ and LM8-LacZ. The labeling ability of KM12SM-LacZ was high ex vivo, but the detection of LacZ-expressing cell aggregates at an accuracy level higher than that in conventional pathological preparations was not possible in the liver metastasis model in the present study. For this, two reasons were considered: Staining of the background liver by X-gal staining; this makes detection of the metastasis of single cells difficult and the inability of single cells to engraft in the liver. This is due to difficulties for single cancer cells to survive in the liver due to rapid blood flow and the presence of many phagocytes in the portal vein. Arlt et al (19) attempted to detect liver metastasis of single cells, but success or failure of the detection was not described in the study. In H\&E-stained preparations, adhered and non-adhered tumor cell aggregates consisting of $\sim$ ten cells were observed in Grade-3 metastasis by light microscopy (Fig. 4C and D). This finding was important to demonstrate that cancer cell aggregates consisting of a specific number of cells moved in the portal vein and engrafted in the liver.

The present study created a liver metastasis model using a LacZ-labeled highly metastatic cell line, KM12SM-LacZ, and investigated metastatic lesions formed by single cancer cells. Arrival of DNA fragments to the liver (Grade-1 metastasis), metastasis in pathological preparations (Grade-3) and macroscopic metastasis on the liver surface were frequently observed, but no intrahepatic metastasis of single cells of KM12SM-LacZ (Grade-2 metastasis) was confirmed in the $\mathrm{X}$-gal-stained sections. By contrast, micrometastasis lesions were observed in H\&E-stained preparations following light microscopy, suggesting that a specific number of cancer cell aggregates is necessary to establish hematogenous metastasis. However, the current model was established within a limited environment, by injection of cancer cells into the spleen, and thus the behavior of cancer cell aggregates in situ remains unknown. Therefore, future studies into unicellular metastasis in situ are warranted.

\section{Acknowledgements}

The authors of the present study thank Ms. Yukiko Iwahara and Aimi Uchida, university students from the Department of Clinical Pharmacy, Tokyo University of Pharmacy and Life Sciences for their valuable technical assistance.

\section{References}

1. Nordlinger B, Guiguet M, Vaillant JC, Balladur P, Boudjema K, Bachellier P and Jaeck D: Surgical resection of colorectal carcinoma metastases to the liver. A prognostic scoring system to improve case selection, based on 1568 patients. Association Française de Chirurgie. Cancer 77: 1254-1262, 1996.

2. Takahashi M, Hasegawa K, Oba M, Aoki T, Sakamoto Y, Sugawara Y and Kokudo N: Repeat resection leads to long-term survival: Analysis of 10-year follow-up of patients with colorectal liver metastases. Am J Surg 210: 904-910, 2015.

3. Mise Y, Imamura H, Hashimoto T, Seyama Y, Aoki T, Hasegawa K, Beck Y, Sugawara Y, Makuuchi M, Nakajima J and Kokudo N: Cohort study of the survival benefit of resection for recurrent hepatic and/or pulmonary metastases after primary hepatectomy for colorectal metastases. Ann Surg 251: 902-909, 2010.

4. Löwenthal D, Zeile M, Lim WY, Wybranski C, Fischbach F, Wieners G, Pech M, Kropf S, Ricke J and Dudeck O: Detection and characterisation of focal liver lesions in colorectal carcinoma patients: Comparison of diffusion-weighted and Gd-EOB-DTPA enhanced MR imaging. Eur Radiol 21: 832-840, 2011.

5. Ueno H, Mochizuki H, Shirouzu K, Kusumi T, Yamada K, Ikegami M, Kawachi H, Kameoka S, Ohkura Y, Masaki T, et al: Actual status of distribution and prognostic impact of extramural discontinuous cancer spread in colorectal cancer. J Clin Oncol 29: 2550-2556, 2011.

6. Fidler IJ: The pathogenesis of cancer metastasis: The 'seed and soil' hypothesis revisited. Nat Rev Cancer 3: 453-458, 2003.

7. Isaka N, Nozue M, Doy M and Fukao K: Prognostic significance of perirectal lymph node micrometastases in Dukes' B rectal carcinoma: An immunohistochemical study by CAM5.2. Clin Cancer Res 5: 2065-2068, 1999.

8. Okada K, Wada T, Ito K, Takagi Y, Aoki T and Koyanagi Y: Investigation of the anti-tumor activity of hepatic Kupffer cells for control of colon cancer micro-metastasis to the liver via the Fas/Fas ligand system. J Tokyo Med Univ 61: 329-335, 2003.

9. Morikawa K, Walker SM, Nakajima M, Pathak S, Jessup JM and Fidler IJ: Influence of organ environment on the growth, selection, and metastasis of human colon carcinoma cells in nude mice. Cancer Res 48: 6863-6871, 1988,

10. Warburton PE, Greig GM, Haaf T and Willard HF: PCR amplification of chromosome-specific alpha satellite DNA: Definition of centromeric STS markers and polymorphic analysis. Genomics 11: 324-333, 1991.

11. Becker M, Nitsche A, Neumann C, Aumann J, Junghahn I and Fichtner I: Sensitive PCR method for the detection and real-time quantification of human cells in xenotransplantation systems. $\mathrm{Br}$ J Cancer 87: 1328-1335, 2002.

12. Oda H, Ogata Y and Shirouzu K: The effect of angiogenesis inhibitor TNP-470 against postoperative lung metastasis following removal of orthotopic transplanted human colon cancer: An experimental study. Kurume Med J 48: 285-293, 2001. 
13. Giavazzi R, Jessup JM, Campbell DE, Walker SM and Fidler IJ: Experimental nude mouse model of human colorectal cancer liver metastases. J Natl Cancer Inst 77: 1303-1308, 1986.

14. Fidler IJ: Orthotopic implantation of human colon carcinomas into nude mice provides a valuable model for the biology and therapy of metastasis. Cancer Metastasis Rev 10: 229-243, 1991.

15. Takiguchi S, Shimazoe T and Kono A: Antitumor effect of camptothecin analog on liver metastatic model of human colon cancer in nude mice. Gan To Kagaku Ryoho 21: 705-708, 1994 (In Japanese).

16. Chen Y, Zou TN, Wu ZP, Zhou YC, Gu YL, Liu X, Jin CG and Wang XC: Detection of cytokeratin 19, human mammaglobin and carcinoembryonic antigen-positive circulating tumor cells by three-marker reverse transcription-PCR assay and its relation to clinical outcome in early breast cancer. Int J Biol Markers 25: 59-68, 2010.
17. Nomoto S, Nakao A, Ando N, Takeda S, Kasai Y, Inoue S, Kaneko T and Takagi H: Clinical application of K-ras oncogene mutations in pancreatic carcinoma: Detection of micrometastases. Semin Surg Oncol 15: 40-46, 1998.

18. Kutun S, Celik A, Cem Kockar M, Erkorkmaz U, Eroğlu A, Cetin A, Erkosar B and Yakicier C: Expression of CK-19 and CEA mRNA in peripheral blood of gastric cancer patients. Exp Oncol 32: 263-268, 2010.

19. Arlt MJ, Banke IJ, Walters DK, Puskas GJ, Steinmann P, Muff R, Born W and Fuchs B: LacZ transgene expression in the subcutaneous Dunn/LM8 osteosarcoma mouse model allows for the identification of micrometastasis. J Orthop Res 29: 938-946, 2011. 